\title{
Du nouveau dans la \\ myopathie de \\ Duchenne
}

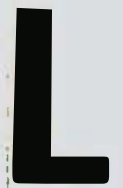

a myopathie de Duchenne est une affection redoutable qui atteint les garçons dans une proportion de I sur 3000 à I sur 5000 . La recherche actuelle est centrée sur le génie génétique, à la poursuite d'une sonde localisée sur le bras court du chromosome X. Les récents travaux d'une équipe de Boston ouvrent une voie nouvelle. Ils sont basés sur l'hypothèse d'un trouble généralisé du métabolisme du calcium et s'effectuent sur des fibroblastes en culture.

Les auteurs utilisent deux tests. Le premier montre qu'à très faible concentration en calcium du milieu de culture $(0,02 \mathrm{mM}$ au lieu de $0,18 \mathrm{mM}$ ), la croissance des cellules normales est arrêtée, alors que celle des cellules myopathiques n'est que modérément ralentie. Le second test utilise une méthode antérieurement décrite par les auteurs : la réplication de l'ADN du virus de l'herpès, prise comme index de fonction cellulaire, est 5 à io fois plus élevée dans les fibroblastes des malades que dans ceux des témoins, en milieu appauvri en sérum et en calcium. Avec cette technique, Io échantillons de malades et trois de femmes conductrices ont été reconnus sans erreur dans un test "à l'aveugle ".

Ces travaux, s'ils sont confirmés, auront une importance considérable pour la reconnaissance des femmes conductrices, le diagnostic prénatal, et aussi peut-être pour la compréhension de la maladie. J.-C. D.

Fingcrnan E, Campisi J, Pardec A. B. Defective $\mathrm{Ca}^{2+}$ metabolism in Duchenne muscular dystrophy: effect on cellular and viral growth. Proc Natl Acad Sci USA 1984; 81 : 7617-21.

\section{Caprice de l'évolution? des gènes de globine sans introns}

es gènes de globine des vertébrés, qui codent la myoglobine et les différentes hémoglobines, sont tous organisés de la même façon. Leurs parties codantes, comme celles de la majorité des gènes des animaux, sont interrompues par des introns en des positions identiques pour les diverses espèces, ce qui implique une conservation des introns depuis 600 à 800 millions d'années. On sait que les légumineuses possèdent une variété d'hémoglobine appelée leghémoglobine. Le gène de la leghémoglobine possède trois introns, ce qui suggère, au cours de l'évolution, une histoire commune plus ancienne encore.

La découverte que viennent de faire Antoine et Niessing n'en est que plus surprenante. La larve aquatique du diptère Chironomus thummi thummi possède au moins 12 hémoglobines différentes qui circulent librement dans l'hémolymphe. On connaît la séquence des acides aminés de plusieurs d'entre elles. Les auteurs ont obtenu quatre clones génomiques différents, qu'ils ont caractérisés et qui sont exprimés in vivo. Aucun des quatre gènes ne possède d'introns.

L'absence d'introns dans une protéine animale n'est pas scandaleuse en soi. Le scandale provient de la présence d'introns dans la leghémoglobine, suggérant que les vertébrés pourraient être plus proches des légumineuses que des insectes. Une première hypothèse serait qu'il s'agisse chez les insectes de " pseudo-gènes ". On sait que ceux-ci proviennent de la réinsertion dans le génome d'ARN messagers souvent viraux, recopiés en ADN. Ces pseudo-gènes ne contiennent pas d'introns. Ils sont modifiés au cours de l'évolution et ne sont le plus souvent pas fonctionnels. Cette hypothèse est donc peu probable dès lors qu'elle devrait s'appliquer à toute une série de gènes, d'autant que les globines de Chironomus sont exprimées. Il faudrait donc admettre une évolution parallèle à partir d'une globine primitive qui aurait pu par exemple contenir trois introns, en avoir perdu un chez les vertébrés et tous les trois chez les insectes, par exemple suivant le schéma :

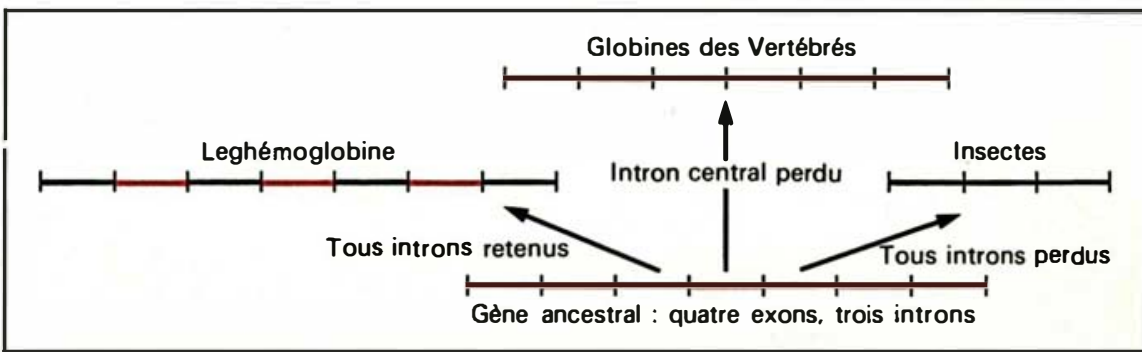

On peut toutefois émettre une hypothèse plus séduisante : le gène de l'hémoglobine aurait été acquis par les légumineuses à une époque beaucoup plus récente que la date de séparation des règnes animal et végétal; il proviendrait d'un transfert d'information entre un animal et une plante qui se seraient trouvés en contact étroit. On ne possède pas d'argument expérimental dans le cas des globines, mais une analogie est suggestive : la bactérie émettrice de lumière Photobacter leiognathi, dont l'hôte est un poisson téléostéen (ponyfish), porte un gène de superoxyde dismutase qui est clairement de type poisson, bien que non identique à celui de son hôte. J.-C. D

Cornish-Bowden A. No introns in insect globin genes. Nature 1984; $310: 724$.

Antoine M, Niessing G. Intron-less globin genes in the insect Chironomus thummi thummi. Nature 1984; $310: 795-8$.

Martin JP, Fridovich I. Evidence for a natural gene transfer from the ponyfish to its bioluminescent bacterial symbiont Photobacter leiognathi. 7 Biol Chem 1984; 256:6080-9. 